Supplement of Biogeosciences Discuss., 12, 14869-14910, 2015

http://www.biogeosciences-discuss.net/12/14869/2015/

doi:10.5194/bgd-12-14869-2015-supplement

(C) Author(s) 2015. CC Attribution 3.0 License.

(c) (1)

Supplement of

\title{
Microbial methanogenesis in the sulfate-reducing zone of surface sediments traversing the Peruvian margin
}

\section{J. Maltby et al.}

Correspondence to: J. Maltby (jmaltby@geomar.de) and T. Treude (ttreude@g.ucla.edu)

The copyright of individual parts of the supplement might differ from the CC-BY 3.0 licence. 


\section{Supplement}
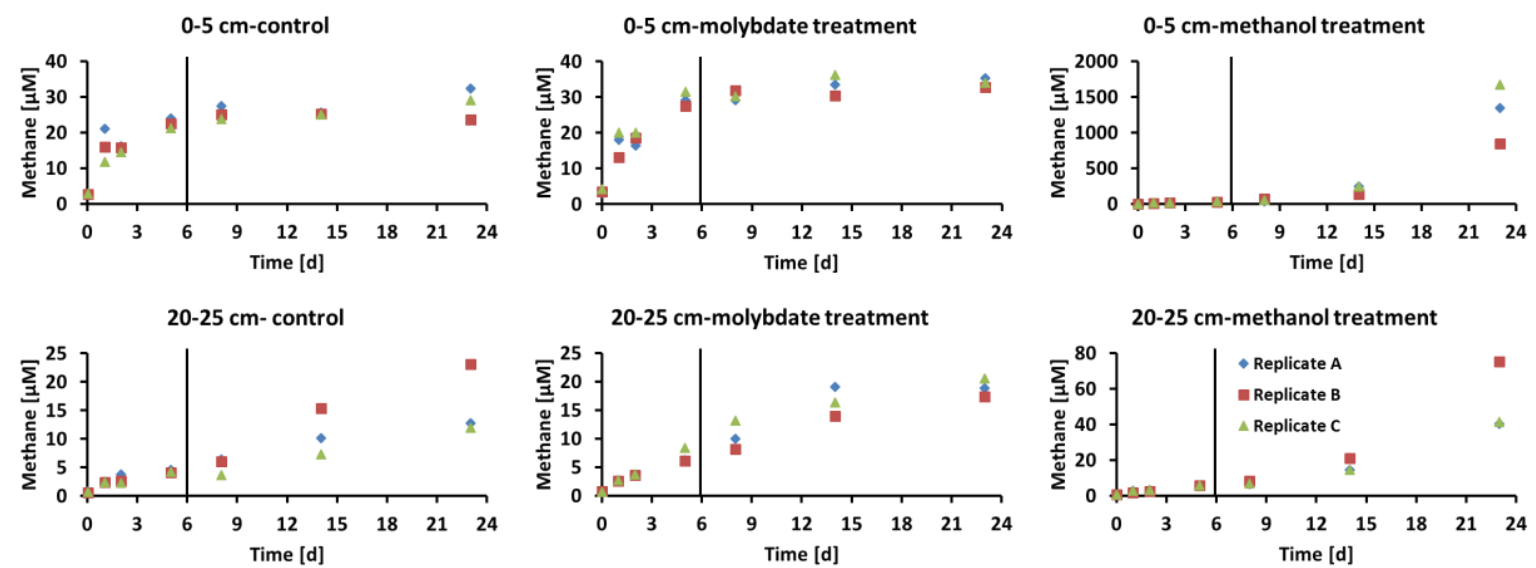

Figure S1: Methane concentration over time in the three different treatments of the sediment slurry experiment in the $0-5 \mathrm{~cm}$ and $20-25 \mathrm{~cm}$ horizon of St. 1 (70 m). "Control" is defined as the treatment with sulfate-rich $(28 \mathrm{mM})$ artificial seawater medium, "molybdate treatment" is defined as the treatment with sulfate-rich artificial seawater medium plus molbydate $(22 \mathrm{mM})$, and "methanol treatment" is defined as the treatment with sulfate-rich artificial seawater medium plus methanol (10 $\mathrm{mM})$. Shown are triplicate measurements per time point. The vertical black line marks the separation of two different phases that were used for methane production rate calculations. Please note the different scale at the y-axis of the methanol treatments. 